\title{
Pemanfaatan Pembelajaran Ict Dalam Optimalisasi Proses Belajar Mengajar Guru SMP
}

\author{
Arief Nugroho Wibowo ${ }^{1}$, Agus Supandi ${ }^{2},{ }^{3}$ Andri ${ }^{4}$, Sigit Widiyarto ${ }^{* 5}$ \\ ${ }^{1}$ Prodi Arsitektur,FTIK Universitas Indraprasta PGRI \\ ${ }^{2}$ Prodi Matematika FMIPA Universitas Indraprasta PGRI \\ ${ }^{4}$ Prodi Informatika FTIK Universitas Indraprasta PGRI \\ 3,5 Prodi Pendidikan Ekonomi Universitas Indraprasta PGRI \\ *email: sigit.widiyanto372@gmail.com
}

\begin{abstract}
The development of information technology and telecommunications greatly affected the world of education. By utilizing technology, education would be more advanced and not be left behind. Not only that, the teaching and learning process would be more effective, efficient, interesting and fun. Unfortunately, not all teachers were able to use technology as a learning medium. SMP N 8 Bekasi is a junior high schools located in Bekasi. Distance from the city of Bekasi to the government center (Jakarta) was about $20 \mathrm{~km}$. With the distance that was not too far, the utilization of technology in the world of education should be very high. But the reality was different. the use of technology to help the teaching and learning process is still very minimal. Especially computers as learning media. This was because the skills in operating a computer were still very minimal. From the results of the situation analysis, what was needed by the teachers in the three schools is ICT (Information Communication Technologies) training. The training was specifically for the operation of some software that could help teachers in the learning process. Some of these software include power point, excel, macromedia flash, and movie maker. In addition to training, there will be initial and final monitoring as well as coaching for partner schools to find out the development of teacher competencies in using instructional media using computers. The target of the outcomes of this program that teachers have the skills and can use computers as learning media. In order to use some additional programs in learning such as Macro Media, Movie Maker, PowerPoint and Microsof Word, the average results of both theory and practice are good enough. It can be concluded that community service activities can help teachers and the learning process in the classroom.
\end{abstract}

Keywords: ICT, Teacher , Junior High School

\begin{abstract}
Abstrak
Perkembangan teknologi informasi dan telekomunikasi sangat mempengaruhi dunia pendidikan. Dengan memanfaatkan teknologi, maka pendidikan akan lebih maju dan tidak akan tertinggal. Bukan hanya itu, dalam proses belajar mengajar pun akan lebih efektif, efisien, menarik dan menyenangkan. Sayangnya, tidak semua guru mampu memanfaatkan teknologi sebagai media pembelajaran.

SMPN 8 Bekasi sekolah menengah pertama yang terdapat di kota Bekasi. Jarak ota Bekasi ke pusat pemerintahan (Jakarta) sekitar $20 \mathrm{~km}$. Dengan jarak yang tidak terlalu jauh tersebut, seharusnya pemanfaatan teknologi di dalam dunia pendidikan sangatlah tinggi. Tetapi kenyataannya berbeda. Pemanfaatan teknologi untuk membantu proses belajar mengajar masih sangat minim. Terutama komputer sebagai media pembelajaran. Hal ini dikarenakan keterampilan dalam pengoperasian komputer masih sangat minim. Dari hasil analisis situasi, hal yang dibutuhkan oleh guru-guru di sekolah tersebut adalah pelatihan ICT (Information Communication Technologies). Pelatihan ini menggunakan metode monitoring awal, pelatihan dan monitoring akhir. Pelatihan ini di khususkan untuk pengoperasian beberapa software yang dapat membantu guru dalam proses belajar mengajar. Beberapa software tersebut antara lain power point, excel, macromedia flash, dan movie maker. Selain pelatihan, diadakan monitoring awal dan akhir serta pembinaan terhadap sekolah mitra untuk mengetahui perkembangan kompetensi guru dalam menggunakan media
\end{abstract}


pembelajaran menggunakan komputer. Tujuan dari Pelaksanaan kegiatan untuk masyarakat ini adalah guru mempunyai keterampilan dan dapat menggunakan komputer sebagai media pembelajaran. Hasil kegiatan menunjukkan bahwa kegiatan ini dapat membiasakan guru untuk menggunakan beberapa program tambahan dalam pembelajaran seperti, Macro Media, Movie Maker ,Power Point dan Microsof Word, hasil rata - rata baik teori dan praktek sudah cukup baik. Dapat disimpulkan bahwa kegiatan pengabdian kepd masyarakat dapat membantu guru dan proses pembelajaran di kelas.

Kata Kunci : ITC, Pembelajaran guru,SMP

\section{PENDAHULUAN}

Zuhra (2011) menyatakan Teknologi Informasi memang menyajikan dan menjanjikan kecepatan, yang merupakan salah satu faktor yang sangat dituntut dalam pengelolaan informasi, . Perkembangan teknologi informasi dan telekomunikasi tidak dapat dihentikan, mau tidak mau, suka atau tidak suka, kita harus mengikutinya. Apabila tidak, maka kita akan tersisih.

Proses belajar mengajar yang efektif dan efisien dapat dilakukan dengan bantuan teknologi. Karena hal tersebut, tidak heran apabila seorang guru dituntut untuk menguasai teknologi agar tidak tertinggal (Cleopatra, M. ,2019).. Penguasaan teknologi sebagai media pembelajaran, selaras dengan konsep kota Bekasi yang menuju kepada smart city. Smart city di bidang pendidikan salah satunya adalah peningkatan kualitas tenaga pendidik (Didit .2016)

SMPN 8 Bekasi terletak di jalan Cipendawa, Bojongmenteng, Rawalumbu, kota Bekasi. Total guru berjumlah 69 guru dan jumlah kelas 45 kelas

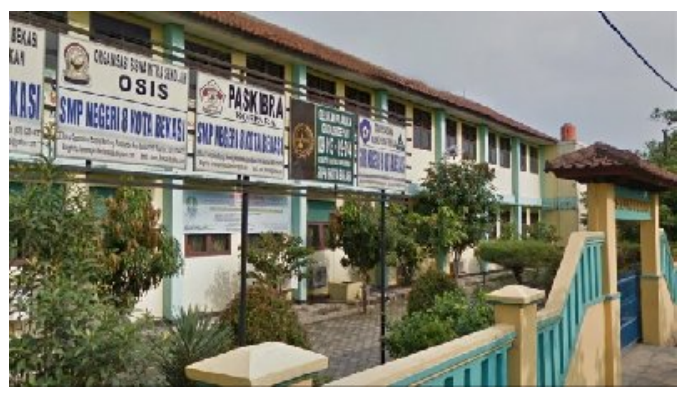

Gambar 1. Gambar Depan SMPN 8 Bekasi

Interaksi dalam proses belajar mengajar di SMPN 8 Bekasi, umumnya menggunakan sistem one way. Selain itu, guru juga terbiasa menulis di papan tulis kemudian menjelaskan. Penggunaan teknologi sebagai media pembelajaran di sekolahan ini belumlah maksimal (Supandi, A.,dkk ,2020). Padahal dengan menggunakan teknologi, selain kegiatan belajar menjadi lebih efektif dan efisien dalam transfer ilmu ke siswa, juga akan lebih menarik dan menyenangkan.

Kendala yang dimiliki oleh guru dalam penggunaan komputer sebagai media pembelajaran adalah kompetensi dalam pengoperasian komputer tersebut. Tidak sedikit guru yang belum memiliki keterampilan dalam mengoptimalkan pengunaan komputer. Untuk itu perlu diadakan pelatihan ICT (Information Communication Technologies). Pelatihan ICT dapat membantu guru dalam mengoperasikan komputer untuk membantu dalam proses belajar mengajar.

SMPN 8 Bekasi merupakan salah satu mitra dalam program PKM ini. Guru di sekolah tersebut belum dapat mengoperasikan komputer secara maksimal sebagai media pembelajaran. Hanya 2 guru yang bisa mengoperasikan. Hal ini dikarenakan pengetahuan dan keterampilan khusus dalam pengoperasian beberapa program yang dapat membantu proses belajar mengajar.

Menindaklanjuti dari permasalahan mitra di atas, kami selaku tim abdimas membuat beberapa program kegiatan pelatihan ICT. Pelaksanaan pelatihan ICT dilakukan di SMPN 8 Bekasi.

\section{METODE PENGABDIAN}

Untuk membantu mitra dalam menyelesaikan permasalahannya, tim telah 
merancang beberapa kegiatan yang dilaksanakan, antara lain :

1. Melakukan monitoring awal terhadap sekolah mitra. Monitoring awal dilakukan untuk mengetahui lebih mendalam tentang kemampuan guru dalam pengoperasian komputer. Selain itu, juga untuk mengetahui sejauh mana penggunaan media komputer untuk membantu guru dalam proses belajar mengajar.

2. Melaksanakan pelatihan komputer. Materi pelatihan adalah beberapa program yang dapat digunakan untuk menunjang proses belajar mengajar. Materi pelatihan komputer antara lain microsoft power point, microsoft excel, macromedia flash, dan movie maker.

3. Monitoring akhir terhadap sekolah mitra. Setelah melaksanakan pelatihan komputer, dilakukan monitoring kembali terhadap sekolah mitra. Monitoring dilakukan untuk mengetahui perkembangan guru dalam menggunakan media komputer dalam proses belajar mengajar. Diharapkan terjadi peningkatan kualitas terhadap penggunaan komputer oleh guru pada sekolah mitra. Monitoring dilaksanakan pada saat pelatihan dan sesudah selesai pelatihan. Tim membagi 3 kelompok guru, guru yang mempunyai kemampuan rendah, sehingga diberikan bantuan maksimal, guru yang mempunyai kemampan sedang dan kemampuan yang tinggi.

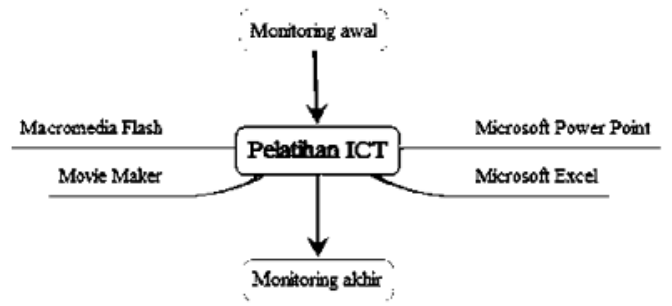

Gambar 1.Denah tahapan kegiatan

PKM.

Langkah-langkah kegiatan yang dilaksanakan seperti terlihat pada gambar 1. Selain kegiatan di atas, pendekatan yang dilakukan oleh tim untuk membantu dalam menyelesaikan persoalan mitra antara lain dengan memberikan penghargaan terhadap tiga perserta terbaik yang mengikuti pelatihan. Hal ini dilakukan agar peserta memiliki antusias dalam mengikuti pelatihan. Selain itu, setiap peserta pelatihan juga akan diberikan fasilitas sertifikat pelatihan.

Tempat pelatihan ICT dilakukan di SMPN 8 Bekasi. Hal ini sebagai partisipasi dari SMPN 8 Bekasi sebagai mitra. Setiap guru dari sekolah mitra juga berpartisipasi sebagai peserta pelatihan. Selain itu, beberapa guru menjadi objek monitoring oleh Tim PKM.

Evaluasi pelaksanaan program adalah dengan melakukan monitoring akhir. Monitoring dilaksanakan terhadap beberapa guru yang mengikuti pelatihan dari sekolah mitra. Memantau bagaimana penerapan dan penggunakan media komputer oleh guru, terutama dengan menggunakan program-program yang telah diajarkan saat pelatihan. Diharapkan, guru dapat memanfaatkan media komputer/laptop untuk membantu proses belajar mengajar di waktu-waktu selanjutnya. Sehingga, keberlanjutan dan kebermanfaatan dari hasil kegiatan PKM benar-benar diterapkan dan dirasakan oleh guru pada khususnya, dan siswa pada umumnya.

\section{HASIL DAN PEMBAHASAN}

Kegiatan pengabdian kepada para guru di SMPN 8 Bekasi diadakan secara bertahap. Materi Macro Mediaflash dan Moviemaker sedangkan Powerpoint dan Microsoft diberikan secara bergiliran. Dari 69 guru yang mengajar ,tim membagi 3 kelompok sesuai dengan kemampuan para guru. Dengan mengadakan tes praktek awal, didapat, 2 orang menguasai dengan baik, 30 guru menguasai tingkat sedang dan tingkat rendah sebanyak 37 guru. Berikut hasil capaian para guru pada pembelajaran macro mediaflash dan moviemaker. 
Tabel.1. Hasil Nilai Rata-Rata Pelatihan

\begin{tabular}{|c|c|c|c|c|}
\hline No & Materi & $\begin{array}{c}\text { Jenis } \\
\text { Tes }\end{array}$ & $\begin{array}{l}\text { Rata } \\
\text { rata } \\
\text { Nilai }\end{array}$ & Ket \\
\hline \multirow{3}{*}{1} & Macro & Teori & 73 & \\
\hline & Media & & & Tampilan \\
\hline & & Praktek & 65 & Gambar \\
\hline & Movie & Teori & 67 & Tampilan \\
\hline 2 & Maker & Praktek & 65 & Gambar \\
\hline \multirow[t]{2}{*}{3} & Power & Teori & 70 & \\
\hline & Point & Praktek & 69 & \\
\hline & & Teori & & \\
\hline & Microsoft & Praktek & 89 & \\
\hline 4 & Word & & 85 & \\
\hline
\end{tabular}

Pada tabel 1 , tertera nilai rata - rata praktek para guru, lebih rendah dari nilai teori. Hal ini dapat dimungkinkan, karena para guru memerlukan waktu lebih lama lagi untuk melatih tahapan materi yang ada. Disamping itu $70 \%$ usia guru sudah diatas 45 tahun. Mereka memerlukan latihan yang lebih banyak, agar tidak lupa, dan terbiasa di kelas menggunakan program yang sudah disampaikan oleh para pemateri.

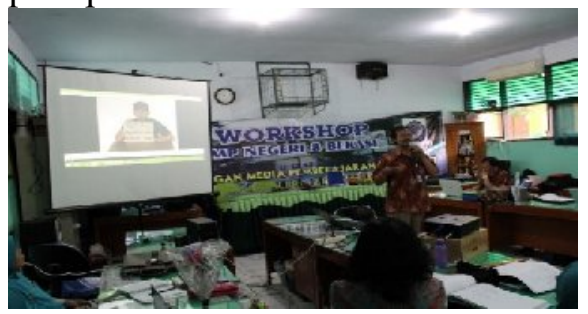

Gambar 3 .Tim Menjelaskan Materi

Program macro flash salah satu materi dobe Flash ( yang dulu bernama Macromedia Flash) salah satu piranti lunak komputer yang menjadi produk unggulan Adobe Systems. Adobe Flash digunakan untuk membuat gambar vektor maupun animasi gambar tersebut. Para guru yang sering menggunakan program ini, guru bidang Matematika, Fisika,Biologi dan bidang mata pelajaran lain. Dalam hal ini guru bidang matematika ,Fisika dan biologi sangat terbantu dengan adanya proram tersebut. Para guru tersebut membuat pembanding ,dari sebelum menggunakan program tersebut, dan setelah menggunakan program di kelas Pembelajaran lebih menarik, aktif ,dan menyenangkan, sehingga nilai post test lebih tinggi dari sebelumnya.

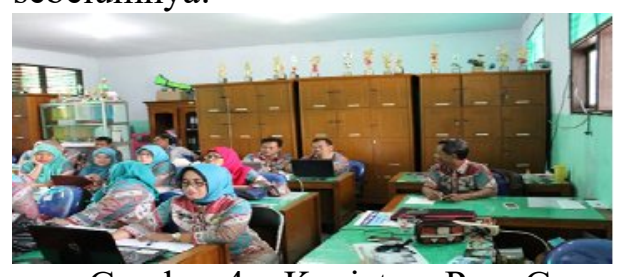

Gambar 4. .Kegiatan Para Guru

Sedangkan windows Movie Maker adalah program atau Software pengolah video yang bawaan dari Windows XP. Movie Maker terinstall sewaktu menginstall Windows Xp Secara otomatis. meskipun program bawaan dan bukannya program yang berdiri sendiri, Movie Maker mampu menjadi program video editing yang handal.

\section{SIMPULAN}

Pengabdian masyarakat kepada khalayak masyarakat, khususnya para guru, merupakan kegiatan yang mampu meningkatkan sumber daya manusia. Para guru yang megajarkan kepada para siswa, akan mampu mendeliver pengetahuan mereka dengan metode dan media yang menarik perhatian siswa, dan pada akhirnya siswa dapat menyerap ilmu pengetahuan dengan baik.

Saran bagi para pemangku pendidikan, agar selalu meningkatkan kompetensi sesuai dengan bidang masing masing. Kegiatan ini mampu mendorong motivasi sekaligus tantangan bagi para pemateri untuk meningkatkan kompetensi. Bagi guru mereka dapat mengembangkan atau minimal mempraktekkan semua yang sudah diberikan dalam pelatihan ICT.

\section{UCAPAN TERIMA KASIH}

Kami mengucapkan terimakasih kepada Ibu Yani,M.Pd selaku wakil kepala sekolah, yang dapat membantu kegiatan pelatihan ini. Kepada para guru dan staf TU SMPN 8 Kota Bekasi, kami ucapkan rasa syukur, karena dapat memberikan kontribusi pada kegiatan ini. Pada kesempatan ini ,kami juga ucapkan 
terimakasih kepada pada kepala sekolah SMPN 8 kota Bekasi, yang dapat memberikan waktu dan partisipasi dalam kegiatan pengabdian kepada masyarakat .

\section{DAFTAR PUSTAKA}

[1] Agung, Y. A 2014).Pengembangan Media Pembelajaran Berbasis ICT Menggunakan Multisim simulations pada Mata Pelajaran Teknik Elektronika Dasar di SMK Negeri 7 Surabaya. Jurnal pendidikan teknik elektro, 3(2).

[2] Ati, A. P., Cleopatra, M., \& Widiyarto, S. (2020). Strategi Pembelajaran dan Pengajaran Menulis Bahasa Indonesia: Tantangan di Era Revolusi Industri 4.0. PROSIDING SAMASTA.

[3] Cleopatra, M. (2019). Impact Of Visual And Verbal Scaffolding On Web-Based Problem Solution Performance In Vocational School Students. International Journal of Education, Information Technology, and Others, 2(2), 35-37

[4] Hadi, S., Puspita, F., Ati, A. P., \& Widiyarto, S. (2020). Penyuluhan Dan Pembelajaran Karakter Melalui Pelaksanaan Idul Adha Pada Siswa Sma. Jurnal Pemberdayaan: Publikasi Hasil Pengabdian Kepada Masyarakat, 4(2), 205-210.

[5] Rahmasiwi, A. (2015). Peningkatan keterampilan proses sains siswa dalam pembelajaran biologi melalui penerapan model pembelajaran inkuiri di kelas XI MIA 9 (ICT) SMA Negeri 1 Karanganyar tahun pelajaran 2014/2015.

[6] Suprapto, H. A. (2018). Strategi Pembelajaran Kewirausahaan Berbasis Teknologi Informasi (TI) Terhadap Peningkatan Minat Mahasiswa Menjadi Wirausaha.
Didaktis: Jurnal Pendidikan dan Ilmu Pengetahuan, 18(1).

[7] Supandi, A., Sahrazad, S., Wibowo, A. N., \& Widiyarto, S. (2020). Analisis Kompetensi Guru: Pembelajaran Revolusi Industri 4.0. PROSIDING SAMASTA.

[8] Surjono, H. D., \& Gafur, A. (2010). Potensi pemanfaatan ICT untuk peningkatan mutu pembelajaran SMA di kota Yogyakarta. Jurnal Cakrawala Pendidikan, 2(2).

[9] Vernia, D. M., Widiyarto, S., Wulansari, L., \& Rusdi, M. (2018). Penyuluhan Dalam Meningkatkan Partisipasi Program Dana Desa. Prosiding Sembadha, 1(1), 72-78.

[10] Widiyarto, S., Wulansari, L., \& Hasanusi, F. S. (2020). Pelatihan "English Communicative" Guna Mempersiapkan SDM Berkualitas dan "Competitive". Intervensi Komunitas, 1(2), 125-131

[11] Widiyarto, S., Wulansari, L., \& Hasanusi, F. S. (2020). Pelatihan "English Communicative" Guna Mempersiapkan SDM Berkualitas dan "Competitive". Intervensi Komunitas, 1(2), 125-131.

[12]Zuhrah, F. (2011). Pentingnya Teknologi Informasi Dalam meningkatkan pelayanan Di Perpustakaan. Jurnal Iqra, 5(01).

[13]S. Soni et al., "Optimalisasi Pemanfaatan Google Classroom Sebagai Media Optimalisasi Pemanfaatan Google Classroom Sebagai Media Pembelajaran Di Smk Negeri 1 Bangkinang," J. Pengabdi. Untuk Mu NegeRI, vol. 2, no. Mei 2018, pp. 17-20, 2018. 